\title{
Dopamine transporter imaging in clinically unclear cases of parkinsonism and the importance of Scans Without Evidence of Dopaminergic Deficit (SWEDDs)
}

Neuroimagem do transportador de dopamina em casos de parkinsonismo clinicamente indefinidos e a importância dos SWEDDs (exames sem evidência de déficit dopaminérgico)

Marco A. T. Utiumi', André C. Felício², Conrado R. Borges'1, Vera L. Braatz', Sheyla A. S. Rezende1, Renato P. Munhoz', Rodrigo A. Bressan ${ }^{3}$, Henrique B. Ferraz², Hélio A. G. Teive ${ }^{1}$

\begin{abstract}
The clinical diagnosis of Parkinson's disease (PD) is susceptible to misdiagnosis, especially in the earlier stages of the disease. Recently, in vivo imaging techniques assessing the presynaptic dopamine transporter (DAT) have emerged as a useful tool in PD diagnosis, improving its accuracy. Objective: It was to illustrate the clinical usefulness of a brain single-photon emission computed tomography (SPECT) DAT ligand, and highlight relevant aspects of scans without evidence of dopaminergic deficit (SWEDDs) in this context. Cases: We described four representative patients with clinically unclear parkinsonian syndromes who underwent [99mTc]-TRODAT-1 SPECT and reviewed the clinical implications. Conclusion: DAT-SPECT is an important, cost-effective, technique for the differential diagnosis of parkinsonian syndromes. Additionally, SWEDD cases present clinical and paraclinical peculiarities that may retrospectively identify them as essential/dystonic tremor. The lack of histopathological data limits further conclusions.
\end{abstract}

Key words: Parkinson disease, scans without evidence of dopaminergic deficit, tomography, emission-computed, single-photon, Tc-99mtrodat-1, dopamine transporter.

\section{RESUMO}

O diagnóstico clínico da doença de Parkinson (DP) pode estar sujeito a erros especialmente nas fases iniciais da doença. Recentemente, técnicas de imagem in vivo que avaliam o transportador de dopamina pré-sináptico (DAT) surgiram como uma ferramenta empregada no diagnóstico da DP, melhorando sua acurácia. Objetivo: Foi demonstrar a utilização clínica de um traçador de tomografia computadorizada por emissão de fóton único (SPECT) e destacar importantes aspectos dos casos de SWEDDs (exames sem evidência de déficit dopaminérgico) neste contexto. Casos: Descrevemos quatro pacientes representativos de síndromes parkinsonianas clinicamente incertas submetidos a [99mTc]-TRODAT-1 SPECT e revisamos suas implicações. Conclusão: O DAT-SPECT é uma técnica importante e eficiente para o diagnóstico diferencial das síndromes parkinsonianas. Além disso, os casos de SWEDDs apresentam peculiaridades clínicas e paraclínicas que podem retrospectivamente identificá-los como tremor essencial ou tremor distônico. As conclusões têm alcance limitado pela falta de dados histopatológicos.

Palavras-Chave: doença de Parkinson, exames sem evidência de déficit dopaminérgico, tomografia computadorizada de emissão de fóton único, Tc-99m-trodat-1, transportador de dopamina.

The parkinsonian syndrome (PK) encompasses several well-known disorders, including (i) Parkinson's disease (PD); (ii) parkinsonism secondary to non-degenerative causes; (iii) atypical degenerative parkinsonism; and (iv) heredodegenerative parkinsonism ${ }^{1-3}$. In our service ${ }^{4}$, among patients with $\mathrm{PK}$, three quarters of them receive the final diagnosis of PD (Fig 1).
The diagnosis of PD is essentially clinical and the most commonly used criteria (UK PDS Brain Bank) are based on three steps (Table 1) 1,2. However, clinicopathologic studies have shown a high rate of false-positives and false-negatives ${ }^{1,5}$. Additionally, the seminal study by Braak and colleagues, showing that the pathological process starts at the brainstem

${ }^{1}$ Movement Disorders Unit, Neurology Service, Internal Medicine Department, Hospital de Clínicas, Universidade Federal do Paraná (UFPR), Curitiba PR, Brazil; ${ }^{2}$ Department of Neurology, Universidade Federal de São Paulo (UNIFESP), São Paulo SP, Brazil;

${ }^{3}$ Department of Psychiatry, UNIFESP, São Paulo SP, Brazil

Correspondence: Hélio A. G. Teive; Rua General Carneiro 1103/102;80060-150 Curitiba PR - Brasil; E-mail: hagteive@mps.com.br

Conflicts of interest: There is no conflict of interest to declare.

Received 01 April 2012; Received in final form 08 May 2012; Accepted 15 May 2012 
and olfactory nucleus, later involving the midbrain and substantia nigra, confirmed the perception that current diagnostic criteria, focusing on motor manifestations of PD, have limited sensitivity to identify the disease in its earliest stages ${ }^{6}$.

In order to improve the accuracy of in vivo diagnosis of $\mathrm{PD}$, investigative efforts have focused on the detection of either structural changes in the substantia nigra or striatal dopaminergic function. While the pathological structural changes have been studied using transcranial ultrasound and magnetic resonance imaging (MRI) techniques, striatal dopaminergic dysfunction can be assessed in three different ways: (1) evaluating the density of presynaptic dopamine transporters (DAT) using positron emission tomography (PET) or SPECT tracers; (2) measuring

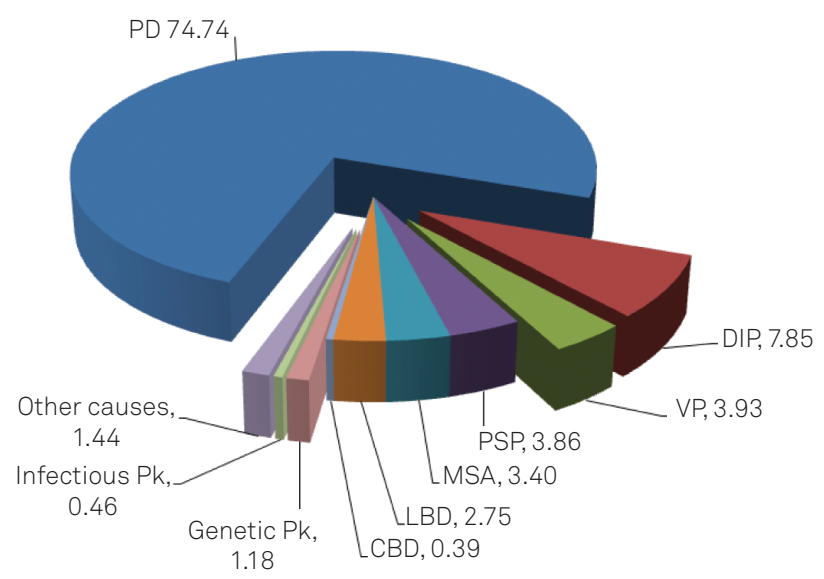

PD: Parkinson's disease; DIP: drug-induced parkinsonism; VP: vascular parkinsonism;PSP:progressive supranuclear palsy;MSA:multiple system atrophy; LBD: Lewy body dementia; CBD: corticobasal degeneration; PK: parkinsonism.

Fig 1. Causes of parkinsonism. Final diagnoses from our movement disorders clinic as presented by Munhoz et al. ${ }^{4}$. All values are presented in percentages $(n=1528)$. dopa decarboxylase enzyme activity as a marker for dopamine turnover using ${ }^{18} \mathrm{~F}$-dopa PET; and (3) identifying vesicular monoamine transporters type 2 with ${ }^{11} \mathrm{C}$ - or ${ }^{18} \mathrm{~F}$-dihydrotetrabenazine $\mathrm{PET}^{7}$.

Additionally, there may be some 4 to $15 \%$ of patients considered to have PD, but who may indeed have normal scans or the so-called scans without evidence of dopaminergic deficit (SWEDD). This acronym is actually a radiological term that arose from previous papers on the literature of clinical trials in PD, particularly the CALM-PD, REAL-PET and ELLDOPA studies ${ }^{8-11}$. Overall, SWEDD patients have signs of $\mathrm{PK}$, but do not have PD, their striatal dopaminergic function seems normal and there is no clinical response to levodopa ${ }^{12}$.

This paper aimed to illustrate the usefulness of DAT imaging using [ $\left.{ }^{99 \mathrm{~m}} \mathrm{Tc}\right]-T R O D A T-1$ SPECT, contextualized in the assessment of four clinical cases, and to review relevant aspects emerging from its use, which includes the dilemma of the cases with SWEDDs.

\section{ILLUSTRATIVE CASES}

\section{Case 1}

A 60-year-old female noticed difficulty with manipulation of objects using her left hand. It started with progressive loss of left hand dexterity, severe enough to affect daily activities, during the previous year. She referred a depressed mood and lack of interest in previously pleasurable activities. There were no relevant comorbidities except for moderate obesity. She was physically inactive and a former smoker. Her mother had hypertension and suffered from an ischemic stroke.

Table 1. The United Kingdom Parkinson's Disease Society Brain Bank clinical diagnostic criteria.

\begin{tabular}{|c|c|c|}
\hline Step 1. Diagnosis of Parkinsonism & Step 2. Exclusion criteria for PD & $\begin{array}{l}\text { Step 3. Supportive criteria for PD } \\
\text { ( } \geq 3 \text { required for definite diagnosis) }\end{array}$ \\
\hline $\begin{array}{l}\text { Bradykinesia(a) and } \geq 1 \text { of the following: } \\
\text { Muscular rigidity; } \\
\text { 4-6 Hz rest tremor; } \\
\text { Postural instability }{ }^{(b)} \text {. }\end{array}$ & $\begin{array}{l}\text { Repeated strokes with stepwise progression } \\
\text { Repeated head injury } \\
\text { Definite encephalitis } \\
\text { Oculogyric crises } \\
\text { Use of neuroleptic or dopamine-depleting } \\
\text { agents at onset of symptoms } \\
>1 \text { affected relative } \\
\text { Sustained remission } \\
\text { Strictly unilateral features after } 3 \text { y } \\
\text { Supranuclear gaze palsy } \\
\text { Cerebellar signs } \\
\text { Early severe disautonomy } \\
\text { Early severe dementia with disturbances of } \\
\text { memory, language or praxis } \\
\text { Babinski sign } \\
\text { Cerebral tumor or communicating } \\
\text { hydrocephalus on neuroimaging } \\
\text { Negative response to large doses of } \\
\text { levodopa (malabsortion excluded) } \\
\text { Exposure to known neurotoxin (e.g. MPTP) }\end{array}$ & $\begin{array}{l}\text { Unilateral onset } \\
\text { Rest tremor } \\
\text { Progressive disorder } \\
\text { Persistent asymmetry affecting side of onset most } \\
\text { Excellent response }(70-100 \%) \text { to levodopa } \\
\text { Severe levodopa-induced chorea } \\
\text { Levodopa response for } \geq 5 \text { y } \\
\text { Clinical course of } \geq 10 \text { y }\end{array}$ \\
\hline
\end{tabular}

PD: Parkinson's disease; MPTP: 1-methyl-4-phenyl-1,2,3,6-tetrahydropyridine; y: years; (a) Delayed onset of voluntary movement with increasing reduction of amplitude and speed of repetitive movements; (b) Unrelated to primary visual, cerebellar, vestibular or proprioceptive dysfunction. 
On examination, there was mild rest tremor affecting the left hand, in addition to moderate bradykinesia, especially for finger tapping. The cranial nerves, muscle strength, deep tendon reflexes, sensory function, coordination and gait were normal. There were no rigidity or postural instability.

Blood tests, including complete blood count, electrolytes panel, thyroid function, liver function and hormone levels, were normal. Brain MRI showed a hyperintense T2/FLAIR image close to the right putamen, indicative of lacunar ischemic lesion. Cervical spine MRI was normal.

A therapeutic trial with piribedil and bupropion brought partial improvement, leaving her clinically stable for about a year, when some degree of motor worsening was noticed. Ropinerole was started. Two months later, during a followup clinical examination, slight residual motor impairment was detected and it responded partially to adjustments in daily dose of ropinerole during the next ten months. Due to doubt in clinical diagnosis, she underwent a [99m Tc]-TRODAT-1 SPECT scan, showing no significant changes (Fig 2A). She was withdrawn of the dopaminergic treatment and on follow-up after 6.5 years she is taking only antidepressants. Symptoms improved progressively, with no evidence of any of the signs of PK.

\section{Case 2}

A 63-year-old female was sent for assessment by her otolaryngologist due to a hand tremor. Her right hand rest tremor was first noticed two years before and progressed slowly, affecting also the contralateral limb. This symptom was exacerbated by anxiety and also worsened during the day. She had been using flunarizine intermittently for about four years to control symptoms of vertigo. Her previous medical and family history were unremarkable. On examination, the Dix-Hallpike maneuver elicited a mild nystagmus with the fast component directed to the right side. Motor examination showed a mild right asymmetric rest tremor in the upper limbs, completely abolished with action. Minimal bradykinesia was detected only on the right hand with repetitive movements. Arm swing was symmetric.

The laboratory evaluation showed TSH levels of 6.05 (normal 4.0). Brain MRI was unremarkable.

The patient was advised to stop flunarizine and treated with clonazepam and levothyroxine. There was minimal improvement after six months and levodopa/benserazide $100 / 25 \mathrm{mg} /$ day was started with moderate response. Dosage was adjusted, remaining on a plateau of clinical manifestations that lasted until the $11^{\text {th }}$ year of the follow-up. During this period, the patient suffered from anxiety disorder and panic attacks, refractory to clonazepan and fluoxetine. These symptoms only responded to venlafaxine $150 \mathrm{mg} /$ day. The limited motor improvement with significant emotional component encouraged the study with [ $\left.{ }^{99 \mathrm{~m}} \mathrm{Tc}\right]-T R O D A T-1$ SPECT scan that showed no abnormalities (Fig 2B). Dopaminergic treatment was gradually withdrawn and until the most recent follow-up visit, 14 years after the first motor symptom, the patient was using only antidepressants, remaining with a slight rest tremor and bradykinesia in her left hand.

\section{Case 3}

A 56-year-old female was referred by her general practitioner because of slowness of voluntary movements and tremor. Her symptoms started on the left hand four months previously. She also complained of a depressed mood and mental slowness. All symptoms begun three weeks before she underwent a bariatric surgery. Family medical history was unremarkable.

General examination showed no significant findings except for obesity. The motor examination showed left upper limb rest tremor, rigidity and bradykinesia.

The laboratory exams and brain MRI were normal.

The initial treatment included levodopa and paroxetine. Four weeks later, she reported mild motor improvement that led to a progressive increase of the levodopa dose. After 12 months, there were no additional motor or non-motor symptoms, and the PK remained stable steady improvement, worsening with emotional stress only. Due to diagnostic uncertainty, a [ $\left.{ }^{99 \mathrm{~m}} \mathrm{Tc}\right]-T R O D A T-1$ SPECT scan was performed, showing reduced tracer uptake in the striatum, more pronounced on the right side (Fig 2C). During the latest clinical follow-up, after three years of disease, her hand tremor was worse and now mild postural instability and motor fluctuation with wearing-off periods were noticed, requiring further adjustments of dopaminergic therapy to levodopa/benserazide $100 / 25 \mathrm{mg} /$ day.

\section{Case 4}

A 37-year-old female was assessed by an orthopedic surgeon and a general practitioner complaining of tremor. Fifteen days before her initial evaluation, the patient noticed rest tremor and difficulties with fine movements of the right hand. A levodopa trial was stopped as there was no evident response. She had suffered from postpartum thyroiditis only. The only known relative with a neurologic problem was her father in law who suffered from PD. On examination, there was a reduction in mobility of the right hand, accompanied by moderate rest tremor that left the extremity in an almost fixed flexed posture. Right hand bradykinesia was evident on clinical examination.

Laboratory tests were normal. Brain MRI showed no structural abnormalities.

She was instructed to restart and remain on levodopa aiming to reach higher doses than previously tried. During the initial seven months of follow-up, there was little improvement in rest tremor, and motor function remained unchanged despite the addition of selegiline to the drug regimen. Due to diagnostic uncertainty, a study with 

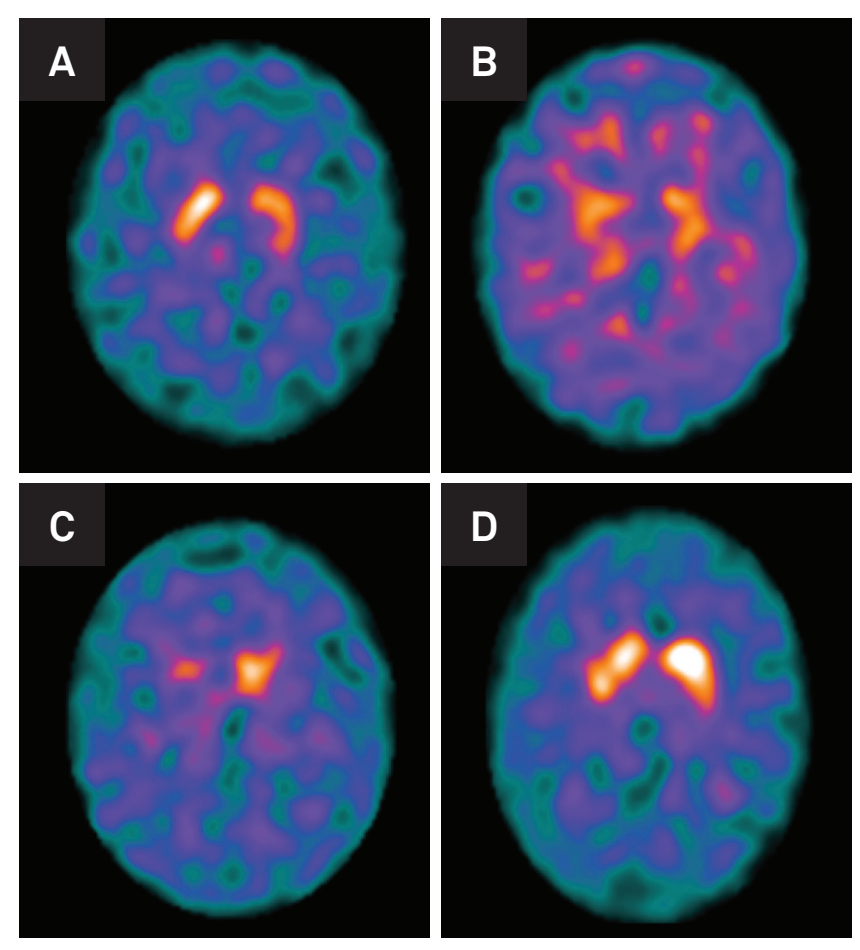

Fig 2. Case-illustrative images of dopamine transporter scan assessed with TRODAT-1 SPECT: (A) case 1, (B) case 2, (C) case 3 and (D) case 4. Only the third image is abnormal, showing most prominent reduced striatal uptake of the ${ }^{99} \mathrm{Tc}$-TRODAT radiopharmaceutical (contralateral to the worse clinical sideaffected: left arm).

[99m Tc]-TRODAT-1 SPECT scanning was performed, showing no abnormalities (Fig 2D). A summary of the clinical picture and final diagnosis are presented in Table 2.

\section{DISCUSSION}

We present our experience with the use of functional imaging for the differential diagnosis of cases of PK. It is important to stress that during clinical evaluations performed by neurologists and non-neurologists, from the beginning of motor symptoms to the final diagnosis, PD was considered at some point in all cases. Prospective clinical evaluation allowed to establish PD as the etiology of case 3 , and this was only possible by means of functional imaging with [99m $\mathrm{Tc}]-$ TRODAT-1 SPECT scan. The remaining three cases were characterized by a more benign course, with features that challenged the initial diagnosis of $\mathrm{PD}$, and a normal [ $\left.{ }^{99 \mathrm{~m}} \mathrm{Tc}\right]-$ TRODAT-1 SPECT scan, consistent with the recently described clinical cases of SWEDDs ${ }^{12-14}$.

Recent clinical trials aimed to verify the effects of dopaminergic therapy in the clinical course of PD and employed functional neuroimaging. The ELLDOPA study used the tracer $\left[{ }^{123} \mathrm{I}\right]-\beta$-CIT in a subgroup of patients and it showed that 21 of the 142 individuals who underwent the examination $(14.7 \%)$ showed a putaminal uptake greater than $75 \%$ of the age-expected putaminal uptake ${ }^{11}$. The REAL-PET study employed ${ }^{18} \mathrm{~F}$-dopa PET and identified 21 cases with normal scans among 186 randomized subjects $(11.3 \%)^{10}$. The CALM-PD-CIT study revealed $4 \%$ of normal scans ${ }^{8,9}$. These studies speculated the possibility that these patients with normal neuroimaging represented either PD cases (possibly early stages) or another condition, such as essential tremor (ET). This intriguing group of patients has since been described as SWEDDs.

Some facts reinforce the idea that SWEDDs differ from PD cases. Schneider and colleagues described ten SWEDDs patients and proposed that all individuals in their series had, in fact, dystonic tremor. Some features were consistent with that: the presence of head tremor, dystonic posturing of the tremulous limb or thumb extension tremor, "flurries" or position/task specificity of tremor, involvement of neck and speech by dystonia, no development of additional features and absence of clear akinesia ${ }^{13}$. The benign clinical and radiological evolution, compared to PD, has also been described by other authors ${ }^{14,15}$. The case 4 described here resembles the patients included in the series of Schneider et al. ${ }^{13}$. Actually, based on their clinical characteristics, SWEEDs patients could be classified into two major groups: tremor dominant and non-tremor dominant SWEDDs, and for each group one

Table 2. Clinical and radiological findings of four cases of parkinsonian syndromes initially referred to our movement disorders service as Parkinson's disease cases.

\begin{tabular}{|c|c|c|c|c|c|c|c|c|c|}
\hline \multirow{2}{*}{ Case } & \multirow{2}{*}{ Age of onset (y) } & \multirow{2}{*}{ Duration $(y)-$} & \multicolumn{4}{|c|}{ Motor signs } & \multirow{2}{*}{$\begin{array}{l}\text { Addl. } \\
\text { signs }\end{array}$} & \multirow{2}{*}{$\begin{array}{c}{ }^{[99 \mathrm{~m} T c]-T R O D A T-1} \\
\text { SPECT }\end{array}$} & \multirow{2}{*}{ Final diagnosis } \\
\hline & & & $\mathrm{B}$ & $\mathrm{R}$ & $\mathrm{T}$ & $\mathrm{P}$ & & & \\
\hline 1 & 59 & 6.5 & + & + & - & - & - & Normal & Vascular Parkinsonism \\
\hline 2 & 61 & 14 & + & - & + & - & - & Normal & Anxiety disorder + Benign Tremulant Parkinsonism \\
\hline 3 & 56 & 4 & + & + & + & + & - & Abnormal & PD \\
\hline 4 & 37 & 2 & + & - & + & - & Dystonia & Normal & Dystonic tremor \\
\hline
\end{tabular}

B: bradykinesia; R: muscle rigidity; T: rest tremor; P: postural instability; PD: Parkinson's disease; y: years. 
may identify the main underlying diagnosis. If one believes this is a distinct group of patients, thus clinical classification could be a first step to address management.

Studies that focused on non-motor symptoms are interesting approaches to address the differential diagnosis of PD versus SWEDDs. Hyposmia occurs in $80-100 \%$ of cases of $\mathrm{PD}^{16,17}$ and it may represents an initial symptom of the disease process ${ }^{6,18}$. The use of the "Sniffin' Sticks" odor-identification test resulted in a sensitivity of 88.2 and $63.2 \%$ with a specificity of 85.7 and $78.6 \%$ for early-onset and late-onset PD, respectively ${ }^{19}$. When the University of Pennsylvania Smell Identification Test (UPSIT) was used in 21 patients with SWEDDs, their scores were significantly higher (better) than those of the PD group and did not differ from control, ET or dystonia groups ${ }^{16}$. A low score would indicate a high probability of PD (accuracy of 97\%) and higher UPSIT scores encourage the search for alternative diagnoses.

On the other hand, the motor symptoms of SWEDDs cases have been elegantly evaluated by Mian and colleagues using position markers ${ }^{20}$. Some aspects differ between PD and SWEDDs, lacking in the latter: flexed trunk and elbow angle, excessive variability of stride length and altered steppingphase coordination. In addition, some findings, not characteristic of ET, were identified in the SWEDDs group: reduced arm swing and absence of gait ataxia ${ }^{20}$.

It is relevant to remember that there are unclear SWEDDs cases responsive to levodopa. Sixel-Döring et al. showed 12 SWEDDs cases ( $14 \%$ of the sample) and 6 of them were responsive to levodopa. One patient was appointed to have dystonic tremor ${ }^{21}$.

The clinical and paraclinical data on SWEDDs suggest that it is not a subtype of PD. Likewise, clinical and neurophysiological substrates identified so far seem to differ between SWEDDs from ET. On the other hand, several of the fully described cases of tremulant SWEDDs end up satisfying criteria for what is considered dystonic tremor. However, due to the lack of histopathological data and a specific marker for either condition, except for PD, a define link is still missing.

Our final questions are: what is the role of DAT-SPECT in the management of patients with parkinsonism and is it cost-effective? Retrospective clinical and pathological studies have shown that the clinical diagnosis of PD has a sensitivity of $65-99 \%$ and a specificity of 8-86\% depending on the familiarity of the professional with the potential diagnoses and the number of manifested parkinsonian signs ${ }^{1}$. This picture improves when strict diagnostic criteria are used at movement disorders services, reaching a sensitivity of $91.1 \%$ and a specificity of $98.4 \%^{5}$.

The rationale for striatal DAT imaging is that this allows in vivo assessment of striatal dopaminergic function in patients with PK. The main SPECT tracers currently used are [ $\left.{ }^{123} \mathrm{I}\right]$-FP-CIT, $\left[{ }^{123} \mathrm{I}\right]-\beta$-CIT and [ $\left.{ }^{99 \mathrm{~m}} \mathrm{Tc}\right]-$ TRODAT- 1 . Basically, the semi-quantitative imaging analysis is based on the placement of Regions of Interest (ROI) in the striatum, which enables to identify DAT density or DAT availability. There is a known gradient of dopaminergic dysfunction that comprehends primarily the putamen contralateral to the affected limb and later involvement of the ipsilateral caudate $^{22}$. The European Association of Nuclear Medicine Neuroimaging Committee has published guidelines on the use of $\left.{ }^{123} \mathrm{I}\right]-\beta$-CIT and $\left[{ }^{123} \mathrm{I}\right]-\mathrm{FP}$-CIT SPECT ${ }^{23}$. The technetium-99m labeled TRODAT-1 is a less expensive and more available tracer than the iodine-123 labeled radiotracers. Its use for the evaluation of clinically unclear parkinsonian syndromes has been demonstrated previously, with a sensitivity and specificity of 100 and 70\%, respectively, and an accuracy of $80 \%$, when it was compared to the last clinical diagnosis performed with an average of two years after the baseline evaluation ${ }^{24}$.

In clinical practice, DAT-SPECT or PET provides a powerful tool to demonstrate processes that implicate loss of dopaminergic nerve terminals, such as $\mathrm{PD}$, multiple system atrophy (MSA), progressive supranuclear palsy, corticobasal degeneration and dementia with Lewy bodies, although it is not useful in their differential diagnosis. When faced with a case of PK, but with normal DAT-SPECT, one must consider other conditions, including ET, psychogenic, vascular and drug-induced parkinsonism, as well as dopa-responsive dystonia ${ }^{25}$. Hence, from the imaging point of view, one should differentiate those patients with and without dopaminergic deficits, and keep in mind that there is a clear cut between groups, but not within groups. To illustrate this, the sensitivity to differentiate PD from ET using DAT imaging may be of $93 \%{ }^{26}$, while in PD versus MSA it is much less reliable ${ }^{27}$. Indications for the use of DAT-SPECT were previously published. According to the NICE criteria ${ }^{2}$, the $\left.{ }^{123} \mathrm{I}\right]$-FP-CIT SPECT should be: (1) considered for cases with tremor in which ET cannot be clinically differentiated from parkinsonism and (2) available to specialists with expertise in its use and interpretation. The indications from the European Association of Nuclear Medicine guidelines are available in Table $3^{23}$.

Finally, regarding cost-effectiveness, Van Laere and colleagues, using a pharmacoeconomic model in the Belgian public health context, studied the economic validity of $\left[{ }^{123} \mathrm{I}\right]$-FP-CIT in the differential diagnosis of ET and neurodegenerative parkinsonism presuming a follow-up of five years ${ }^{28}$. The initial investment of $€ 900 /$ patient resulted in an additional 1.198 "adequately treated years" (ATY). After the five years period, the cost difference between the cases handled with DAT-SPECT and those diagnosed solely on clinical assessment grounds, would fall to $€ 429 /$ patient. With an estimated prevalence of $60 \%$ of neurodegenerative parkinsonism, it would mean a small additional cost of $€$ 358/ATY. Using the same model to the Italian public health reality, the use of [ $\left.{ }^{123} \mathrm{I}\right]$-FP-CIT SPECT adds 1.8 ATY at a cost 
Table 3. European Association of Nuclear Medicine indications for DAT SPECT studies using 123-iodine-labeled radiopharmaceuticals.

\begin{tabular}{|c|c|c|}
\hline Indications & Potential indications & Contraindications \\
\hline $\begin{array}{l}{\left[{ }^{123} \mid\right] \text { FP-CIT imaging is indicated for patients }} \\
\text { with CUPS: } \\
\text { - It helps differentiate ET from parkinsonian } \\
\text { syndromes related to PD, MSA and PSP. } \\
\text { - On its own, it is unable to discriminate } \\
\text { between them. } \\
\text { [123|]FP-CIT imaging is indicated for the } \\
\text { differentiation of DLB from other dementias. }\end{array}$ & $\begin{array}{l}\text { Establishment of early diagnosis of } \\
\text { neurodegenerative Parkinsonism. } \\
\text { Assessment of disease severity. } \\
\text { Differentiating patients with presynaptic } \\
\text { PK from those with other forms of PK (e.g. } \\
\text { between PD and neuroleptic-induced PK). }\end{array}$ & $\begin{array}{l}\text { Pregnancy. } \\
\text { Breast feeding: mothers should interrupt } \\
\text { breast feeding for } 24 \mathrm{~h} \text { if SPECT is indicated. } \\
\text { Inability to cooperate with the procedure. }\end{array}$ \\
\hline
\end{tabular}

saving of $€ 442$ per patient. This favorable cost-benefit ratio remains with a prevalence of neurodegenerative parkinsonism of up to $55 \%{ }^{29}$. Therefore, in the context of European public health service, the use of DAT-SPECT could save resources and keep patients with PK on proven beneficial therapy over a longer period. The use of the least expensive and more available $\left[{ }^{99 \mathrm{~m}} \mathrm{Tc}\right]-$ TRODAT-1 has the potential to further reduce the cost-benefit ratio.

In conclusion, challenging movement disorders are not uncommon. This becomes even more relevant when the patient presents at an early stage of the disease process without the most striking manifestations of the parkinsonian syndrome. For these cases, the use of DAT-SPECT shows some promising clinical and economical advantages. With the more widespread use of this technology, the SWEDDs cases will become more common in routine clinical practice. Current literature suggests they are different from PD cases and have a better prognosis. However, details about their management and histopathology remain to be clarified.

\section{References}

1. Litvan I, Bhatia KP, Burn DJ, et al. SIC Task Force appraisal of clinical diagnostic criteria for parkinsonian disorders. Mov Disord 2003;18:467-486.

2. National Collaborating Centre for Chronic Conditions. Parkinson's disease: National clinical guideline for diagnosis and management in primary and secondary care. London: Royal College of Physicians; 2006.

3. Pankratz ND, Wojcieszek J, Foroud T (Updated July 9, 2009). Parkinson disease overview. In: GeneReviews and GeneTests: Medical Genetics Information Resource (database online). Copyright, University of Washington, Seattle, 1997-2011. Available at: http://www.genetest. org. [cited 2011 November 8].

4. Munhoz RP, Werneck LC, Teive HAG. The differential diagnoses of parkinsonism: findings from a cohort of 1528 patients and a 10 years comparison in tertiary movement disorders clinics. Clin Neurol Neurosur 2010;112:431-435.

5. Hughes AJ, Daniel SE, Ben-Shlomo Y, Lees AJ. The accuracy of diagnosis of parkinsonian syndromes in a specialist movement disorder service. Brain 2002;125:861-870.

6. Braak H, Tredici KD, Rüb U, de Vos RAl, Steur ENHJ, Braak E. Staging of brain pathology related to sporadic Parkinson's disease. Neurobiol Aging 2003;24:197-211.

7. Brooks DJ. Imaging approaches to Parkinson disease. J Nucl Med 2010;51:596-609.

8. Parkinson Study Group. Dopamine transporter brain imaging to assess the effects of pramipexole vs levodopa on Parkinson disease progression. JAMA 2002;287:1653-1661.

9. Parkinson Study Group. A randomized controlled trial comparing pramipexole with levodopa in early Parkinson's disease: design and methods of the CALM-PD Study. Clin Neuropharmacol 2000;23:34-44.
10. Whone AL, Watts RL, Stoessl AJ, et al. Slower progression of Parkinson's disease with ropinirole versus levodopa: the REAL-PET Study. Ann Neurol 2003;54:93-101.

11. Fahn S, Oakes D, Shoulson I, et al. Levodopa and the progression of Parkinson's disease. N Engl J Med 2004;351:2498-2508.

12. Fahn S, and the Parkinson Study Group. Does levodopa slow or hasten the rate of progression of Parkinson's disease? J Neurol 2005;252:IV37-IV42.

13. Schneider SA, Edwards MJ, Mir P, et al. Patients with adult-onset dystonic tremor resembling parkinsonian tremor have scans without evidence od dopaminergic deficit (SWEDDs). Mov Disord 2007;22:2210-2215.

14. Marek K, Jennings D, Seibyl J. Long-term follow-up of patients with scans without evidence of dopaminergic deficit (SWEDDs) in the ELLDOPA study. Neurology 2005;64(Suppl 1):S274.

15. Bain PG. Dystonic tremor presenting as parkinsonism: long-term follow-up of SWEDDs. Neurology 2009;72:1443-1445.

16. Silveira-Moriyama L, Schwingenschuh P, O'Donnell A, et al. Olfaction in patients with suspected parkinsonism and scans without evidence of dopaminergic deficit (SWEDDs). J Neurol Neurosurg Psychiatry 2009;80:744-748.

17. Doty RL. Olfaction in Parkinson's disease. Parkinsonism Relat Disord 2007;13(Suppl):S225-S228.

18. Lim S, Lang AE. The nonmotor symptoms of Parkinson's disease - an overview. Mov Disord 2010;25(Suppl 1):S123-S130.

19. Santin R, Fonseca VF, Bleil CB, Rieder CRM, Hilbig A. Olfactory function and Parkinson's disease in Southern Brazil. Arq Neuropsiquiatr 2010;68:252-257.

20. Mian OS, Schneider SA, Schwingenschuh P, Bhatia KP, Day BL. Gait in SWEDDs patients: comparison with Parkinson's disease patients and healthy controls. Mov Disord 2011;26:1266-1273. 
21. Sixel-Döring F, Liepe K, Mollenhauer B, Trautmann E, Trenkwalder C. The role of ${ }^{123}$-FP-CIT-SPECT in the differential diagnosis of Parkinson and tremor syndromes: a critical assessment of 125 cases. J Neurol 2011;258:2147-2154.

22. Marshall V, Grosset D. Role of dopamine transporter imaging in routine clinical practice. Mov Disord 2003;18:1415-1423.

23. DarcourtJ, BooijJ, Tatshc K, et al. EANM procedure guidelines for brain neurotransmission SPECT using ${ }^{123}$-labelled dopamine transporter ligands, version 2. Eur J Nucl Med Mol Imaging 2010;37:443-450.

24. Felicio A, Godeiro-Junior C, Shih MC, et al. Evaluation of patients with Clinically Unclear Parkinsonian Syndromes submitted to brain SPECT imaging using the technetium-99m labeled tracer TRODAT-1.J Neurol Sci 2010;291:64-68.

25. Scherfler C, Schwarz J, Antonini A, et al. Role of DAT-SPECT in the diagnostic work up of parkinsonism. Mov Disord 2007;22:1229-1238.
26. Asenbaum S, Pirker W, Angelberger P, Bencsits G, Pruckmayer M, Brücke T. [123I]beta-CIT and SPECT in essential tremor and Parkinson's disease. J Neural Transm 1998;105:1213-1228.

27. Felicio AC, Shih MC, Godeiro-Junior C, Andrade LA, Bressan RA, Ferraz HB. Molecular imaging studies in Parkinson disease: reducing diagnostic uncertainty. Neurologist 2009;15:6-16.

28. Van Laere K, Everaert L, Annemans L, Gonce M, Vandenberghe W, Borght TV. The cost effectiveness of 123I-FP-CIT SPECT imaging in patients with an uncertain clinical diagnosis of parkinsonism. Eur $J$ Nucl Med Mol Imaging 2008;35:1367-1376.

29. Antonini A, Berto P, Lopatriello S, Tamma F, Annemans L, Chambers M. Cost-effectiveness of 123I-FP-CIT SPECT in the differential diagnosis of essential tremor and Parkinson's disease in Italy. Mov Disord 2008;23:2202-2209. 